\title{
UNA CUESTIÓN DE SÍMBOLOS Y LA BÚSQUEDA DE LA UNIDAD*
}

\author{
Lisa Block de Behar \\ Ciencias de la Comunicación; Universidad de la República, \\ Montevideo
}

«To fix our ideas suppose players playing with dice...» Ch. S. Peirce, «Design and Chance»

«Don Alejandro aspiró alguna vez a ser diputado, pero los jefes políticos le cerraron las puertas del Congreso del Uruguay. El hombre se enconó y resolvió fundar otro Congreso de más vastos alcances. (...) concibió el propósito de organizar un Congreso del mundo que representaría a todos los hombres de todas las naciones.»

J. L. Borges, «El Congreso»

* Una versión diferente a la que aquí se propone, en inglés, fue la comunicación presentada en la sesión plenaria del 12 de junio de 1994 en el V Congreso de la I.A.S.S. (International Association for Semiotic Studies), en Berkeley, California. La referencia a los ángeles se justifica desde el principio, por una apelación a los suficientemente cercanos «genii loci». 
A pesar de los excesos con que se ha trivializado en torno a temas y figuras de ángeles, las eminencias de la reflexión ${ }^{1}$ y la imaginación ${ }^{2}$ contemporáneas no han dejado de frecuentarlos. Tal vez fueron las redes satelitales o los ubicuos mensajes de una incontenible comunicación mediática o las lecturas de Walter Benjamin o la proliferación angélica de Paul Klee o fue el advenimiento del cine, el acontecimiento que dio lugar a una nueva generación de ángeles. No sería aventurado conjeturar que, cualquiera de esas razones, estrechamente vinculadas entre sí, no le son nada ajenas.

Llama la atención la frecuencia bibliográfica, filmográfica, musical, la profusión de obras de todo tipo en las que los ángeles abundan y si bien hoy pocos se preguntarían «si diez mil (ángeles) podrían bailar en la punta de una aguja» o "por qué (los ángeles) no son más interesantes que las sorprendentes variedades de insectos que estudian los naturalistas» ${ }^{3}$, interesa el precedente de su estatuto de intermediación entre dos mundos, la transmisión de mensajes en silencio que se les atribuye, su movimiento a través del espacio, entre lo visible y lo invisible, el anuncio que da testimonio de otros reinos, su constante fugacidad que es permanencia. Las ambivalencias de la condición angelológica resultan válidas para atender algunos aspectos del lenguaje cinematográfico y las propiedades de la palabra en la imagen electrónica, en general: dicha o escrita, muda y en movimiento, la palabra se ve. Silencio y voz, palabra y pensamiento, coinciden en una misma visión, un pase inquietante que borra las fronteras entre ver y soñar, decir y pensar, decir y desear, decir y mostrar, todo a la vez.

La palabra puesta en imagen sintetiza diferencias, atraviesa límites: el ojo que ve, oye; la imagen en movimiento contrae voces y figuras; en el cine, «to show» and «to tell» no se requieren como acciones opuestas ni rivales. La animación del cine que es emoción y movimiento, motiva la palabra, una naturaleza doble y a la vista. La imagen muestra y dice, muestra lo que dice, concurre a realizar el milagro de la mirada o un elogio de la mirada, ad miranda: se dice, se oye, se lee, se mira, solo se ve y, solipsismos al margen, en el silencio y oscuridad de la sala no queda nada detrás ni fuera de esa visión que intercepta la pantalla.

1 Michel Serres (La légende des anges), Michel de Certeau, Massimo Cacciari ( $L$ 'angelo necessario), Marco Bussagli (Storia degli angeli), y otros.

${ }_{2}$ W. Wenders, J. L. Godard siguen un camino no demasiado diferente en un siglo que no los escatimó cinematográficamente: J. von Sternberg, Buñuel, ángeles de colores y exterminadores varios.

3 Ch. S. Peirce, «Fraser's The Works of George Berkeley», Writings of Charles S. Peirce. A Chronological Edition. 1867-1871, vol. 2. Yo traduzco. 
¿Qué habría argumentado el obispo Berkeley frente a esa impresión de los sentidos? Para él serían también estas «verdades tan claras que para verlas nos basta abrir los ojos» ${ }^{4}$. Sin darnos cuenta, en un segundo, Augenblick, se diría en alemán, un golpe de vista, permite atisbar un instante de eternidad, como si la brevedad del episodio lo arrojara fuera del tiempo; el cine respira ese aire neoangélico que da luz a otra versión de la «ténébreuse et profonde unité,/ Vaste comme la nuit ou comme la clarté» que Baudelaire confunde intentando restablecer correspondencias entre sentidos diferentes, vislumbrando las estrellas que desde un séptimo cielo iluminan vagamente un arte que, mientras tanto, hace con la imagen tiempo.

Más allá de las figuras animadas por la luz y el movimiento, el cine difundió nuevos híbridos de imágenes verbales y visuales, promovió tensiones estéticas diferentes habilitando visiones, registrando, no hace mucho, las metamorfosis de palabras escritas que se transforman en las cosas que representan, imágenes magistrales muestran la magia de un movimiento, una prestidigitación que la naturaleza del lenguaje y sus recursos desconocía hasta hace poco. Como en los pasajes de «Prospero's Books» ${ }^{5}$, repentinamente la imagen ya no es ilustración de la dicción sino pasa a ser la visión imposible de su idea. Es en el cine donde la aparición del hombre invisible no fue inverosímil, ni los fantasmas, inauditos.

Semejante al anuncio evangélico de la gestación, un nuevo gesto de deixis anuncia otro lenguaje de los ángeles, una comunicación por mensajeros que se comprometen en un trámite de pasaje, sin requerir contraseñas para sortear fronteras, entre afuera y adentro, en el límite de la ficción, al borde del más allá, entre el cielo y la tierra, suspendidos, suspenden los dualismos esquemáticos que reducen a oposición el género, biológico, gramatical, literario; discurren en un lenguaje interior que el cine pretende hacer visible. En el cine, los ángeles también pasan en silencio, una meditación, una mediación, medio dios medio humanos, mediando entre espacios y especies, los cruzan. Decían algunas leyendas que los ángeles eran tan numerosos, que se apartaban de Dios y separados de la divinidad, caían convertidos en demonios. Las caídas desde el espacio divino al espacio humano multiplicaron leyendas, teorías y doctrinas que coinciden en reconocer una misma fractu-

4 Borges cita a Berkeley en «Nueva refutación del tiempo», Otras inquisiciones (1952). (1992).

Peter Greenaway en su versión cinematográfica de The Tempest, de Shakespeare 
ra: o bien fue la separación la que provocó la caída o bien fue la caída la que provocó la separación. En ambos casos la catástrofe es consecutiva: la separación da origen a lo diabólico (diabolos ${ }^{6}$ : «el que desune, que separa») y la re-unión restablece lo simbólico. De ahí la unión entre universos diferentes que el símbolo recuerda. Para Peirce es precisamente ese el objetivo del universo semiótico, «el Tercer Universo», («the Third Universe») ese tercero que «comprende todo aquello cuyo ser consiste en un poder activo para establecer conexiones entre objetos diferentes, especialmente entre objetos en Universos diferentes» ${ }^{7}$. Su Tercer Universo podría asimilarse al Orbis Tertius inscrito en la cartografía antigua o en el cuento de Borges, el medio donde se cruzan esas Nadas Aéreas («those Airy Nothings») con la Realidad Bruta («the Brute Actuality»).

En esta época de síntesis o sin tesis es necesario reflexionar sobre el encuentro planetario cotidiano de las diversidades de una actualidad que, sin desconocerlas, tiende a contraerlas. Como si se hubiera convocado un congreso universal, es posible compartir una re-unión, un conjunto en un lugar común, un tópico, donde se advierte tanto la diversidad de los elementos como el movimiento de retorno, la vuelta por medio de una unidad satelizada, una especie de apocatástasis secular que nos remite a cierta instancia inicial, anterior, imprecisa.

Palabra y cosa a la par, el lugar común atenúa las diferencias, las asimila en una misma affinitas: prójimo próximo, por próximo semejante. Compartidos, los mismos límites reducen las diferencias entre palabra e imagen, entre el objeto referido y el objeto que refiere, entre discursos performativos y constativos, entre lenguaje y metalenguaje, entre teoría y ficción. La reducción no se verifica solo en una lengua: un proceso de síntesis desvanece los límites entre idiomas diferentes por medio de un cruce semántico disimulado entre palabras sintácticamente cercanas. No es un proceso reciente pero anticipa - poéticamentelas confusiones o eliminaciones desmesuradas al final de un milenio, al final de un siglo, que no las escatimó. Entre tantos finales reiteradamente previstos - de oposiciones, de referentes, de poesía, de teoría, de historia, de guerras ${ }^{8}$ - una realidad desaparece aplastada por los

6 Diaballein se compone de dia «a través» y de ballein de Ballo, lanzar, tirar, golpear, caer o dejar caer.

7 «The first comprises all mere Ideas, those airy nothings to which the mind of the poet, pure mathematician, or another might give local habitation and a name within that mind»... The second Universe is «that of the Brute Actuality of things and facts". Citado por Thomas Sebeok en The Play of Musement (1981).

8 J. Baudrillard, La Guerre du Golfe n'a pas eu lieu (1993). 
espectros de su representación; a diario la imagen tecnológica confunde la realidad con nada.

Como esa confusión no se advierte, es doble la desaparición y aviva, en otros términos, dos antiguas querellas (de las imágenes, de los universales) en una sola cuestión. ¿La mundialización de las imágenes universaliza la falta de representación? Todo aparece o desaparece en ese «black hole» cuadrado de pantallas que dejan ver que no dejan ver, donde se desploma, a domicilio, «el microcosmos de un universo que colapsa» o «los vacíos plenos de estrellas colapsadas» ${ }^{9}$, «au bord du néant [qui] nous donne le néant en nantissement» ${ }^{10}$, el extraño aval con que Breton sostiene el humor negro al margen del abismo.

Es justo abordar este tema relativo a la reunión y síntesis de diversidades en un congreso ${ }^{11}$, ya que nadie olvida que desde su origen, congressus designaba en latín, como ahora, la «acción de encontrarse», aun cuando haya sido adoptado más tarde, en nuestras lenguas, con significados más escabrosos que en este caso no se reivindican. Solo cuando pierde ese sentido erótico de unión inicial malavenida, congreso pasa a designar, más austeramente, una reunión de especialistas convocada para estudiar la síntesis que comprende la diversidad, una operación lógica o antropológica de larga historia y remotos mitos que confirman «el carácter antagonista del mundo» como revelación de la vocación simbólica. Aquí «congreso» alude a un hecho, un cuento, un nombre y una cosa; como el «I think» de Peirce, denota «la unidad del pensamiento», subrayando que «la unidad del pensamiento no es sino la unidad de consistencia de la simbolización, en una palabra (la implicación del ser) y pertenece a cualquier palabra» ${ }^{12}$

Por más que Th. A. Sebeok dijera que «'símbolo' es uno de los términos de los que más se ha abusado» que «tanto tiende a aparecer sobrecargado grotescamente o, al contrario, reducido (..) hasta una nulidad absurda» ${ }^{13}$, se sabe que esta oscilación entre plenitud y agota-

9 Roger Penrose, The Emperor's New Mind. Concerning Computers, Minds and Laws of Physics (1991: 329).

10 A. Breton, Anthologie de l'Humour noir (1966: 222).

11 Congressus «action de se rencontrer» d'où «union sexuelle», dérivé de lat. congredi «se rencontrer», de cum-(co) et gradi (marcher). Le mot a été introduit au sens $\mathrm{d}^{\prime}$ 'uunion sexuelle», propre au XVIè. et XVIIè. et à l'origine de la spécialisation juridique ancienne d' «épreuve légale destinée à constater l'impuissance du mari (avec le témoignage d'une matrone ou sage-femme), cas invoqué pour annuler un mariage». Alain Rey. Le Robert. Dictionnaire historique de la langue française (1992).

12 Writings of Ch. S. Peirce. A Chronological Edition. 1857-1866. Vol. 1 (1982). «Lowell Lecture XI, 1866». Yo traduzco.

13 Th. A. Sebeok, Contributions to the Doctrine of Signs (1985). Yo traduzco. 
miento, una versión de la vigencia ambivalente de «replenishment and exhaustion», además de ser el binomio estético prevaleciente, forma parte de nuestra inquietante práctica diaria. No es necesario advertir desde ya que se descarta cualquier intención de agregarle a símbolo significados nuevos. Más aún, a fin de suspender los excesos de su profusión semántica, se intenta rescatar aquí uno de los sentidos que symbolon tenía en sus orígenes y que los numerosos y variados contextos, interpretaciones y teorías fueron mitigando.

Ni semejanza ni contigüidad, para Peirce el símbolo es «un signo (que) refiere al Objeto y denota en virtud de la Ley». Es por este aspecto legal, convencional, que señala Peirce, que el símbolo se opondría a la noción de «Suerte (Chance) que es indeterminación, es libertad. Pero esa acción de libertad resulta de la más estricta regla de ley» 14 .

«La suerte cambia todo \& la suerte cambiará esto» dice Peirce en el mismo ensayo. De ahí que la tesis de que la suerte ${ }^{15}$ es realmente operativa en el universo, ese fenómeno que Peirce denomina tychism, es una forma de caer, un «caso» que se mantendrá en otras lenguas (fr. choir, ital. cadere, esp. caer); es un azar, un caso, una caída, una parte de su cosmología evolutiva pero también la caída es fatalidad del símbolo y en varios sentidos es su suerte: una suerte y una caída, otra silepsis que reúne en una voz sentidos contradictorios que en esta reunión no se pueden evitar ni pueden sorprender. Tanto como confesaba asombrarse «El ingenuo» de que

«No hay en el orbe una

Cosa que no sea otra, o contraria o ninguna» ${ }^{16}$.

Reprimía su asombro David Brodie -el personaje del cuento y libro epónimos- ante la posibilidad de que coincidieran en un solo nombre significados diferentes y al mismo tiempo opuestos. No habría que sorprenderse, sin embargo, ante el hecho de que «el verbo to cleave (valga) por hendir y adherir». Un mismo verbo significa «separar» y

14 Ch. S. Peirce, «Design and Chance». En Writings of Ch. S. Peirce, 1879-1884. Vol. 4 (1986). Yo traduzco.

15 Chance est issu de l'évolution du lat. cadere «tomber» (choir) preis pour un féminin, propremet «action de tomber», spécialement employé en lat. au jeu des osselets. A. Rey. Le Robert. Op. cit.

16 J. L. Borges, La moneda de hierro (1976). 
«unir», un ejemplo a varias puntas ya que como «congreso», designa e ilustra a la vez la segmentación y la unión. Borges subraya esa sola voz dentro de una serie de ejemplos donde habla de un congreso y de la unión carnal, sin decir que en latín una misma designación no los diferenciaba ${ }^{17}$.

Todavía nos afectan las consecuencias de estas chances-caídas y aunque las versiones de la pérdida de la inocencia sean de las más dramáticas o más repetidas, no está de más recordar que para los griegos esta chance-caída se refería inicialmente al juego de kubos, el lance de dados, un signo de reconocimiento o de hospitalidad en una comunidad compartida, antes de radicar en su acción el origen de los símbolos. Un juego de huesitos que, encontrados también en cavernas prehistóricas, superando las coincidencias de una semántica transidiomática se designa como knucklebones, en inglés, osselets, en francés y taba, en español, derivado del árabe, y es a ese juego ancestral al que apostamos en esta presentación. Se intenta así aludir a símbolos, a caídas, fragmentos, fracturas, «breaking of the vessels» - diría en términos cabalísticos- la rotura de los cántaros o el desmoronamiento de torres, provocación traumática de diferencias idiomáticas, de dispersiones y reuniones carnales o espirituales, de congresos, una serie lúdica y teórica que, según Peirce, recorre etapas de tychism (caída), synechism (continuidad), terminando en agapism, esa «tesis de que el amor o la simpatía tiene real influencia en el mundo y, de hecho, es la agencia evolutiva del universo» ${ }^{18}$.

Los mitos coinciden en imaginar caídas similares: se precipitan ángeles, habitantes del Pardés-Paraíso, híbridos andróginos de Platón, se rompen los cántaros y desmoronan las torres y, en todos los casos, una presunción que justifica el acontecimiento por soberbia y rivalidad del saber. Como en tiempos arcaicos, la comunicación universal, sin límites, de la actualidad, se verificaría en el cielo; hoy, sin ir Más Allá - con mayúsculas - en los satélites. Una lengua común anterior, sin fisuras, primero; la división en lenguas o sexos, como castigo, después. En el Symposium, Aristophanes, menos autor que personaje de Platón, habla de la soberbia de los andróginos que, siendo nuestros ancestros, compartiendo nuestra naturaleza humana y nuestra condi-

17 J. L. Borges, «El informe de Brodie» (1974). En el párrafo inicial, el narrador, antes de transcribir y traducir el informe de Brodie advierte que omitirá algún versículo de la Biblia y un «curioso pasaje sobre las prácticas sexuales de los Yahoos que el buen presbiteriano confió pudorosamente al latín».

${ }_{18}$ Cita de Ch. S. Peirce en «Introduction», Nathan Houser and Christian Kloesel, The Essential Peirce. Selected Philosophical Writings (1992). Yo traduzco. 
ción, no eran como nosotros. En ese pasado, o no se distinguía ningún sexo o se reconocían tres pero no dos. Como si previendo la rigidez de los paradigmas opositivos, la filosofía ya hubiera apelado a un tercer orden del discurso apto para superar la lógica binaria de los contrarios, del sí y el no.

Su forma era diferente «la forma de cada ser humano como un todo era redonda, con espalda y lados formando un círculo, pero tenían cuatro brazos y un igual número de piernas, y dos caras (...) se enrollaban en un círculo (...) eran terribles por el poder y la fuer$\mathrm{za}$, tenían pensamientos altivos y conspiraban contra los dioses» ${ }^{19}$ a tal punto que Zeus y los otros dioses decidieron «cortar a cada uno en dos» de manera que fueran «más débiles y al mismo tiempo más útiles (...) habiendo aumentado en número, y caminarán parados sobre dos pies». Sacrificio de la unidad o de la terceridad, la pérdida consiste en una división en dos. Es por eso que «Cada uno de nosotros no es sino una parte, un símbolo (token) de un ser humano, cortado como un pez, dos de uno; cada uno busca la otra parte necesaria para combinarse» ${ }^{20}$. Tal vez también por eso, Peirce, en «An American Plato» ${ }^{21}$ sin mayores aclaraciones afirmó que «la respuesta general a la pregunta ‘¿Qué es el hombre?' responde 'que es un símbolo'» ${ }^{22}$. (La palabra en griego por lat. tessera, por ingl. token es sumbolon y hace alusión, además de los objetos que se rompen en dos, a cada uno de los pedazos conservados que, en combinación de una pieza con la otra dan prueba de la identidad para quien las presente.)

«Las palabras son símbolos que postulan una memoria compartida» dice Borges en «El Congreso»: «Los místicos invocan una rosa, un beso, un pájaro que es todos los pájaros, un sol que es todas las estrellas y el sol, un cántaro de vino, un jardín o el acto sexual.» Las palabras del narrador anuncian el final de «El Congreso», un cuento que sucede en Montevideo, en el Uruguay, mi pequeño país y, secretamente, abarca el universo. La fidelidad de la cita revela las dualidades que contrae la palabra en español. Cita es el encuentro sentimental e intelectual, transexual o no, transtextual, siempre, pecado bíblico o banquete griego, no desconocen texto o sexo, ni el secreto de «La secta

19 The Dialogues of Plato, vol. II, 190b. (1991). Yo traduzco.

20 Ibid. 191e.

21 Tomo el título del Review de Peirce sobre Royce's Religious Aspect of Philosophy (1885). En N. Houser and Ch. Kloesel. Op. cit.

${ }_{22}$ Writings of Ch. S. Peirce. A Chronological Edition. 1857-1866, vol. I (1982). «Lowell Lecture XI, 1866». 
del fénix» ${ }^{23}$ ni el «plaisir du texte» ${ }^{24}$. ¿Quién no se preguntaría si hablan los ángeles? Sexo y verbo desde el principio conciliados como diversidad y unidad en un mismo conocimiento ${ }^{25}$ concebido inmediatamente después de la Caída, cuando yâdá significaba en hebreo tanto «saber» como «yacer».

«Type or token», el universo hecho pedazos por el conocimiento, la separación de los campos y disciplinas. La ambición de los andróginos, como las emanaciones divinas que hacen estallar los cántaros, como la tempestad que hizo naufragar la utopía, la nave y los libros de Próspero estrellándose

«a brave vessel

Dashed all to pieces»

al borde de una isla. No hay dioses que soporten el desafío ni la (pre)potencia y los símbolos se quiebran tal vez para llegar a reunirse. Fiel a su Musa, Aristófanes, entre bromas e interludios, antes de ceder la palabra a Sócrates y Agathon, repite que «el enamorado desea unirse y fundirse con su amada, convertirse en uno de dos». La causa radica en que fue esta «nuestra naturaleza antigua, y éramos todos. Entonces Eros es el nombre y la causa del deseo y la búsqueda de la totalidad (...) antes éramos uno (...); existe la sospecha de que si no estuviéramos bien dispuestos respecto a los dioses, de nuevo seríamos partidos en dos y andaríamos como la gente que aparece moldeada de perfil en las lápidas funerarias, serruchada en dos por la nariz, nacidos como 'split dice'» ${ }^{26}$. Dados y Sumbola a la par.

Si la relación entre el símbolo y la trinidad aparece recurrentemente no se debe solo a la «compulsión que dirige» volver a «the funhouse of rampant triplicities» de las que hablan Umberto Eco y Thomas Sebeok en su prefacio a The Sign of Three ${ }^{27}$, ni por padecer de la «triadoma-

\footnotetext{
23 J. L. Borges, Ficciones (1944).

R. Barthes, Le plaisir du texte (1973).

${ }^{25}$ Génesis II. IV, 1. «L'homme connut Eve, sa femme...». La nota aclara que «Le verbe yâdá savoir, connaître» est régulièrement employé pour signifier les rapports sexuels, tant en parlant de l'homme que de la femme. (...) Même expression dans les autres langues sémitiques, avec des verbes signifiant «connaître». L'initiation à un acte enveloppé de mystère nous semble à l'origine de cet emploi du verbe «connaître». La Bible. Ancient Testament (1956).

26 The Dialogues of Plato. Op. cit., 193a. Yo traduzco.

27 Dupin, Holmes, Peirce. The Sign of Three (1983). Yo traduzco.
} 
nía», una enfermedad contra la que previene Peirce cuando confiesa que «no tengo una predilección marcada, en general, por las tricotomías» aunque admita «que no es raro que sean las preferidas» ${ }^{28} \mathrm{Sin}$ embargo, «Nadie supondrá que deseo reivindicar ninguna clase de originalidad reconociendo la importancia de la tríada en filosofía. Desde Hegel, casi todos los pensadores con imaginación han hecho lo mismo. La originalidad es la última de las recomendaciones de las concepciones fundamentales. Al contrario, el hecho de que las mentes de los hombres se han inclinado desde siempre a las divisiones tripartitas es una de las consideraciones que se formulan en su favor» ${ }^{29}$.

Si me detengo nuevamente en esta economía trinitaria del pensamiento de Peirce no es solo por haber renegado o superado los binarismos paradigmáticos de las articulaciones estructurales saussureanas sino por tratar de regresar a la unidad desde la terceridad por medio de híbridos y divisiones, del reconocimiento de los «Terceros intermediarios», de la intermediación que la actualidad propicia con una extensión y frecuencia inusuales. "Un centauro es una mezcla de hombre y caballo. Filadelfia queda entre Nueva York y Washington. Tales terceros podrían denominarse Terceros intermediarios o Terceros de comparación» dice Peirce en el mismo texto y es esa mención de los híbridos como un tiers arbitre o tercero en discordia, un ajeno al dilema, el extranjero - un estatuto amparado por «las figuras de la alteridad» o de la ilusión geográfica, el lugar que da lugar a la ficción que interesa destacar aquí.

Podría haberse previsto que superadas las limitaciones rigurosas y abstracciones sistemáticas impuestas por planteamientos teóricos tajantes, las investigaciones en curso, de y sobre la actualidad, articularían disciplinas, contextualizarían conocimientos, conciliando una búsqueda cultural actual que no se verifica en un medio aislado sino entre medios diferentes. Por eso, además de distinguir cada medio en particular, interesa un medio nuevo, un medio más: el que está en el medio. Se abre un hueco, que se forma y es figura entre dos: entre natural y cultural, entre afuera y adentro, entre secular y sagrado, entre mostrar y decir, entre visual y verbal, entre oral y escrito, entre periodístico y literario, entre científico y poético, entre masivo y académico, entre doctrinas y ficciones, un medio, mediato y mediático, donde la imaginación histórica, teórica y estética, se contrae intentando combinar

28 Ch. S. Peirce, Op. cit. 1.568-569. Citado por Sebeok en «One, Two, Three Spell UBERTY» (In lieu of an Introduction). Ibidem. Yo traduzco.

${ }_{29}$ Ch. S. Peirce, «A Guess at the Riddle». En N. Houser and Ch. Kloesel. Op. cit. 
esos fragmentos, restaurar fracturas, resolver fracciones y quebrados. La masificación de los medios se entiende en otro sentido: los medios están en todo y todo está en los medios. Dos quebrados: dos medios entre dos medios, dos dividido dos entre dos dividido dos, simplificando, uno dividido uno da uno, es decir, tres veces uno. En todos los casos se trata de dividir, de medios, un mi-lieu, un lugar entre dos, entre medios, «en el breve vértigo del entre», decía Octavio Paz.

A pesar de la necesidad de conocer, de analizar que es separar, de aplicar doctrinas y disciplinas, las realizaciones contemporáneas tienden a esa búsqueda de una unidad - más que única, inicial- que pretende recuperar, a partir de la diversidad de saberes y de idiomas, algunas coincidencias que las condiciones epistemológicas y estéticas de la situación actual legitiman. La reflexión actual se debate entre medios diversos, se precipita en el medio, en la encrucijada, el lugar de cruce e intersección donde las diferencias por proximidad se confunden, donde no sorprende que la casualidad, que es una forma de la coincidencia, sea rutina.

Con la imagen de una Babel desmoronándose al frente de su libro La ricerca della lingua perfetta, Umberto Eco, al empezar la introducción previene: «La utopía de una lengua perfecta no solo ha obsesionado a la cultura europea. El tema de la confusión de las lenguas y la tentativa de darle remedio gracias al reencuentro o a la invención de una lengua común a todo el género humano, atraviesa la historia de todas las culturas» ${ }^{30}$. Son las primeras palabras del libro y, tal vez sin proponérselo, extienden a un texto voluminoso, la búsqueda que Borges resume en unas líneas de «El Congreso»: «Me hospedé en una módica pensión a espaldas del Museo Británico, a cuya biblioteca concurría de mañana y de tarde, en busca de un idioma que fuera digno del Congreso del Mundo. No descuidé las lenguas universales; me asomé al esperanto —que el Lunario sentimental califica de 'equitativo, simple y económico'- y al Volapük, que quiere explorar todas las posibilidades lingüísticas, declinando los verbos y conjugando los sustantivos. Consideré los argumentos en pro y en contra de resucitar el latín, cuya nostalgia no ha cesado de perdurar al cabo de los siglos. Me demoré asimismo en el examen del idioma analítico de John Wilkins, donde la definición de cada palabra está en las letras que la forman. Fue bajo la alta cúpula de la sala que conocí a Beatriz.»

30 U. Eco, La ricerca della lingua perfetta (1993). Yo traduzco. 
Hace diez años, muy cerca del Research Center for Language and Semiotic Studies que creó Th. A. Sebeok, a Douglas Hofstadter se le ocurrió dedicar un voluminoso libro a Bloomington y proponer fórmulas de una "Magic Cubology» — hasta aquí siguen implicados más cubos, tejas y rúbricas - recuperando ${ }^{31}$ en su manera metamágica las posibilidades polisémicas de una firme o frágil «tessera» o símbolo. Da cuenta 32 de un alfabeto en el que las letras que tienen una función gráfica distintiva dejaran de diferenciar, representaran tanto un fonema como otro, «una Total unificación de Todos los Tipos» ${ }^{33}$, «la treta que consiste en lograr la saturación: llenar el espacio» ${ }^{34}$. Hofstadter y Kim pasaron años dibujando lo que un amigo denominó «ambigramas». Un agravante más que no previó Saussure en sus denuestos contra la escritura. Por eso, esa unificación no es totalmente ajena a las «diferancias» de Derrida, aunque desconozcan sus formulaciones filosóficas; tampoco reivindican el «espíritu» autor de todas las escrituras, esa aspiración literal que requiere la articulación de aleph y que da lugar a todas las letras o al aleph, una imagen literal de Borges, la síntesis en diversidad, al pie de la letra. «The 'A' Spirit» ${ }^{35}$ que describe Hofstadter reivindica una «esencia platónica» singular que reconoce que «la forma de una letra es la manifestación superficial de abstracciones mentales profundas». Con la llegada de las computadoras, «no es difícil disponer de una máquina de hacer ' $A$ ' con una variedad infinita de output potencial» ${ }^{36}$ y ya no es imposible «aproximar la visión de una unificación de todos los tipos» ${ }^{37}$. Da la impresión de que «Cada tantos siglos hay que quemar la Biblioteca de Alejandría», es lo que dice uno de los personajes de «El Congreso». A veces ese incendio puede empezar por una letra.

En el Fedro, Thamus, rey de Egipto, tenía razón en dudar de la invención de Thot o Hermes. La escritura, la primera tecnología dedicada a registrar y conservar la fugacidad, se proponía representar, hacer presente lo ausente. Eficaz, oculta, sospechosa. En tanto que remedio, reúne la peligrosa ambigüedad del farmakon, en tanto que

31 Douglas R. Hofstadter, Methamagical Themas. Questing for the Essence of Mind and Pattern. An Interlocked Collection of Literary, Scientific, and Artistic Studies (1985).

32 Ibid. Comenta Donald Knuth's Article.

33 Ibid. 272.

34 Ibid. 264. Alude al libro de Scott Kim Inversions «in which a single written specimen or 'gram', has more than one reading, depending on the observer's point of view".

35 Ibid. 279.

36 Ibid. 264.

37 Ibid. 261. 
instrumento, las peligrosas ambivalencias del sirviente. Un golem se anima por la letra y por la obliteración de la letra se desploma, hecho de tierra en la tierra.

A medida que pasa el siglo cada vez creemos más que creemos menos; sin embargo, este descrédito creciente que desestima la representación, desde los discursos retóricos hasta las imágenes que los disimulan, tal vez refuerce una creencia en las circunstancias, inmediatas, discutiblemente inmediadas, que, presentes, prescindentes de la representación, están ahí, sin pretender prever las incertidumbres de un Más Allá más o menos seguro, sin pretender acceder a los prolongados anhelos de utopías más o menos aisladas o fantásticas. Son esas circunstancias que, adversas a meras especulaciones o a fantasías políticas, contemplan la radicación en un lugar, celebrando los argumentos de los lugares comunes, en un presente en el que coincidimos. «El Congreso del Mundo comenzó con el primer instante del mundo y proseguirá cuando seamos polvo. No hay un lugar en que no esté».

No se trata de avivar el «furore etimologico» ni de consagrar una lengua perfecta en la que los nombres, como quería Cratilo, estuvieran en una correspondencia natural o necesaria con las cosas, ni de darse "a una caza desaforada de la etimología», como previene Eco, para demostrar parentescos remotos o coincidencias filológicas de raíces con las que el siglo XIX nutrió más que suficientemente sus búsquedas históricas, filológicas y biológicas. Interesa trazar algunas líneas comunes en el pensamiento contemporáneo, proponer una síntesis de diversidades apta para alcanzar la unidad más allá de consagraciones teológicas, superando la facilidad de las oposiciones binarias o la limitación de una numeración que, triádica, solo agregue un término a la serie. No se habla de unidad para reducir tres a dos o dos a uno sino para recuperar «uno» más como principio, como comienzo de una serie abierta, que como limitación cuantitativa de una unidad monotesista: «Sin embargo no voy a adelantar esta especulación más allá, ya que puede ser ofensiva a los prejuicios de algunos que están presentes», digo parafraseando a Peirce ${ }^{38}$.

38 Ch. S. Peirce, Writings of Ch. S. Peirce, vol. I (1982), 503. «In many respects, this trinity agrees with the Christian trinity: indeed I am not aware that there are many points of disagreement. The interpretant is evidently the Divine Logos of word; and if our former guess that a Reference to an interpretant is Paternity be right, this would be also the Son of God. The ground, being that partaking of which is requisite to any communication with the Symbol, corresponde in its function to the Holy Spirit». 
Uno, un comienzo, un origen de creación, un principio lúdico, de recreación, después del final donde las palabras hacen juego, combinan y apuestan esas combinaciones, como si nuevamente se jugara para comprometer los símbolos con la poesía, con las tabas o con los dados. Un coup de dés jamais n'abolira le hasard, resume en un verso un mundo, o dos, su destrucción, su fragmentación de golpe y su restitución por vías transidiomáticas, re/velando por medio de unos cubos arrojados al azar la profunda coincidencia más allá de la superficie diferencial de los idiomas. El símbolo se encuentra en plenitud en la intersección de dos esferas de existencia (combinando exterior, interior, el mundo físico y espiritual, lo visible y lo invisible). Tal vez aluda a los andróginos, a la caída y suerte de los símbolos, a la sospechosa ley del azar, al golpe de dados, de dos dados o de un mismo dado duplicado por idiomas diferentes en un mismo verso y las posibilidades de restitución (una palabra clave) por la intraducción poética, esa figura con que designo tanto la imposibilidad de traducir o el acceso a una traducción muy profunda más allá de los significados que los nombres segmentan o simplifican. En ese lance, es la diferencia de los idiomas la que está en juego.

Ajeno a los deplorados afanes positivistas por encontrar una Ursprache que explique genealógicamente un origen común, la intraducción vale en Borges, en la gran poesía, como ejemplo de síntesis en la diversidad. Búsqueda - poética, teórica- - de las reliquias de una lengua única, inicial, anterior, interior, indivisible, la presunción de una unidad nominal prebabélica que aparece recurrente en sus ensayos, que constituye un punto de partida de su ficción.

Borges descubre la magnífica ironía de Dios a partir de un lenguaje de hierro, de su lenguaje blindado que es el de un ciego, habla del rojo Adán ${ }^{39}$, de otros más rojos yuxtapuestos en sus propios nombres: Red Scharlach. Esas voces cruzadas reclaman una lengua edénica o adámica, donde Ma Vipère de Lettre ${ }^{40}$, bífida y seductora, una lengua partida, de partida y de llegada, un salvoconducto que burla las aduanas por medio de una clave simbólica, tentará al poeta que procura, más allá de los límites idiomáticos, recuperar la com-prensión de una lengua si no única por lo menos unida o universal. Por medio de un dispositivo onomasio-semasiológico extravagante el poeta o el filósofo, desafía las fronteras, impugna el rigor de una historia, parodia las propiedades lingüísticas básicas (arbitrariedad, linealidad); no transgrede

39 En hebreo, tierra es Adama, rojo es Adom y sangre es Dam.

40 J. Laforgue, Les complaintes. «Complainte du pauvre-chevalier errant» (1880). 
pero tampoco observa las normas sintácticas por una semántica casi perversa, extendiendo la consecutividad no como efecto ni en el tiempo sino en un lugar (lugar no espacio, Ort no Raum).

Por ahí es posible volver a las circunstancias, destacar el lugar que habilita la relación entre los elementos materiales, el continente ${ }^{41}$ que hace posible el encuentro, orientándonos, primero, hacia el oeste, el punto desde donde se definen los puntos, segundo, al oeste de América, cerca de Los Angeles. Por eso anotaba que desde hace algún tiempo no rechazo la tentación a venerar a los genii loci y los invoco, citando a Walt Whitman, gracias a un epígrafe que pertenece a Sebeok ${ }^{42}$ :

Solitary, singing in the West, I strike up for a New World.

Desde este cercano far-west, dos veces oeste, dos veces occidental, west \& west, doble ve doble, una $u$ turn nos retorna al comienzo cuando hablábamos de las dualidades de esa chance-caída. Es inevitable recordar que el lat. occidens, es participio presente de occidere, un verbo compuesto de $o b$ - y cadere «caer», al que nos venimos refiriendo desde el principio, una caída que, sin desconocer las otras, se refiere a la puesta de los astros, del sol, especialmente, cuyo poniente es occidente. Sin embargo esta vez tampoco se trata de Der Untergang des Abendlandes, aunque también la caída sea doble.

Los congresos, los viajes, los encuentros, los transportes metafóricos y efectivos, las emisiones planetarias satelitales, propician coincidencias transidiomáticas en las que no parece demasiado rebuscado un individuo que permanezca atento a una misma imagen oyendo en inglés, leyendo en francés y entendiendo en español. Indiferente a las diferencias, comparte una pluralidad de códigos y medios que, desde la comodidad doméstica de las noticias difundidas por los mismos informativos, entiende ubicuos. El poeta hace de esa variedad anodina una tentativa de originalidad, comprometiendo las palabras desde su origen, un acceso impensable, indispensable, apto para recuperar, por distintos procedimientos poéticos, un principio presumible que es reserva de resonancias, sonidos y sentidos multiplicados por el regreso hacia palabras distintas y varios silencios.

41 Es una de las definiciones filosóficas de espacio: el continente donde se reúnen los objetos materiales.

42 Th. A. Sebeok, Semiotics in the United States (1991). Yo traduzco. 
En los límites de un mundo que no disimula el aturdimiento global de sus estridencias tecnológicas, parece cada vez más apremiante sondear el fondo latente en las palabras, aspirar la profundidad que guarda discretos los sentidos de otras épocas, avistar tiempos diferentes solapados en una misma actualidad, avivando los presentimientos del presente. Este rescate de sentidos entredichos es, por lo menos, doble: alguien, filósofo o poeta, descubre en una misma palabra otra manera de significar, una suerte de anagrama que, sin alterar la combinación de los sonidos, habilita otra dirección de la lectura revelando la novedad contradictoria que interpreta, como descubrimiento, una instancia semántica anterior.

A veces solo sorprende como un fuego de palabras, un pase lúdico casi incandescente, un corto circuito del discurso que deslumbra con el ardor y el candor de jugar a varios sentidos al mismo tiempo, con el riesgo de una apuesta verbal que quema las etapas de la sucesión salvando los sentidos de una palabra que en sus cambios permanece. Sobresalta ese despliegue - que no es abuso de la filología - ya que apuntan, simultáneos, sentidos que la propia historia ha mitigado, denunciando una «verdad» que cuenta desde el origen. Es ese «placer de descubrir una etimología» que sentía y decía Borges, de actualizar por una voz, en una vez, la historia que sigue «temblando en el cuerpo de su plurivocidad». Una palabra vuelve sobre sí misma, sin repetirse, se dobla -en más de un sentido- como para dejar oír voces del pasado. La intraducción imprime así un movimiento de retroducción, «an act of insight» como dice Peirce «la sugestión abductiva» que nos llega «como un rayo». Sus elementos, "se encuentran en nuestras mentes antes de que seamos conscientes de su existencia» pero es la idea de reunir lo que nunca antes habíamos soñado reunir lo que ilumina la nueva sugestión ante nuestra contemplación» ${ }^{43}$. Ese «elemento de libertad y originalidad (que) persiste en un universo que ha alcanzado un estado de equilibrio entre suerte y ley» ${ }^{44}$, el lance de dados, la reunión del símbolo, la reunión en un Congreso, el Congreso que, en un cuento, se identifica con el mundo, el cuento que lo relata, refieren la indisociabilidad de la palabra y el mundo, son confusiones que la representación actual —como en los orígenes-propicia.

43 Citado de Peirce por Th. A. Sebeok and Jean Umiker-Sebeok en «You Know my Method». The Sign of Three. Op. cit., p. 18.

44 Citado de Peirce por N. Houser and Ch. Kloesel. Op. cit. XXXIII. Yo traduzco. 


\section{Referencias bibliográficas}

BARTHES, R. (1973). Le plaisir du texte. Paris: Seuil.

BAUdRILlARD, J. (1993). La Guerre du Golfe n'a pas eu lieu. Paris: Galilée.

LA BIBLE. Ancient Testament (1956). Trad. et notes de Édouard Dhorme.

Paris: La Pléiade, Gallimard.

Breton, A. (1966). Anthologie de l'Humour noir. Paris: J. J. Pauvert.

BORGES, J. L. (1944). Ficciones. Buenos Aires: Emecé.

- (1952). «Nueva refutación del tiempo». Otras inquisiciones. Buenos Aires: Emecé.

- (1974). El informe de Brodie. Buenos Aires: Emecé.

- (1976). La moneda de hierro. Buenos Aires: Emecé.

BuSSAGLI, M. (1991). Storia degli angeli. Milan: Rusconi.

CACCIARI, M. (1986). L'angelo necessario. Milan: Adelphi.

Eco, U. (1983). Dupin, Holmes, Peirce. The Sign of Three, Th. A. Sebeok. Bloomington: Indiana University Press.

- (1993). La ricerca della lingua perfetta. Roma-Bari: Editore Laterza fare l'Europa.

HofstAdTER, D. R. (1985). Methamagical Themas. Questing for the Essence of Mind and Pattern. An Interlocked Collection of Literary, Scientific, and Artistic Studies. New York: Bantam Books.

Houser, N., KloEsel, Ch. (1992). The Essential Peirce. Selected Philosophical Writings. Bloomington: Indiana University Press.

LAFORGUE, J. (1880). Les complaintes. «Complainte du pauvre-chevalier errant». Paris.

PEIRCE, CH. S. (1982). Writings of Ch. S. Peirce. A Chronological Edition. 1857-1866. Vol. I. Bloomington: Indiana University Press. «Lowell Lecture $\mathrm{XI}, 1866 . »$

- (1984). «Fraser's The Works of George Berkeley». Writings of Charles S. Peirce. A Chronological Edition. 1867-1871. Vol. 2. Bloomington: Indiana University Press.

- (1986). «Design and Chance». Writings of Ch. S. Peirce. 1879-1884. Vol. 4. Bloomington: Indiana University Press.

Penrose, R. (1991). The Emperor's New Mind. Concerning Computers, Minds and Laws of Physics. New York: Penguin Books.

Plato (1991). The Dialogues of Plato. Vol. II. Translated with comment by R. E. Allen. New Haven: Yale University Press.

REY, A. (1992). Dictionnaire historique de la langue française. Paris: Le Robert.

SEBEOK, TH. (1981). The Play of Musement. Bloomington: Indiana University Press.

- (1985). Contributions to the Doctrine of Signs. Bloomington: University Press of America.

- (1991). Semiotics in the United States. Bloomington: Indiana University Press.

Serres, M. (1993). La légende des anges. Paris: Flammarion. 